\title{
Researching conferences as spaces of valuation: a pragmatic approach
}

Working paper, Draft of 11 December 2021

Susanne Koch (Email: $\underline{\text { s.koch@cwts.leidenuniv.nl) }}$

Centre for Science and Technology Studies (CWTS), Leiden University (The Netherlands) and Centre for Research on Evaluation, Science and Technology (CREST) and DSI-NRF Centre of Excellence in STI Policy, Stellenbosch University (South Africa)

\begin{abstract}
:
Scientific conferences are not only sites of knowledge exchange and networking. They are also spaces of valuation that are constitutive of epistemic cultures. At conferences, scholars (re-) negotiate what counts as good research, what kind of scholarship is considered valuable and which epistemic properties matter for their field. This negotiation sometimes happens explicitly, but more often through evaluative acts: statements of reasoning and justification, questions and remarks, and evaluative emotional utterances that include literal and figurative expressions of appreciation, scepticism, rejection, etc.
\end{abstract}

Combining conference ethnography with a pragmatic approach borrowing insights from linguistics offers a way to identify and interpret such evaluative acts in conference talk. An analysis of data from the $3^{\text {rd }}$ International Forest Policy Meeting (IFPM3), a virtual event with participants from across the globe, serves as illustrative case. Text materials generated through observing participation (field notes, transcripts, chat comments and abstracts) show how forest policy researchers ascribe worth to studies characterised by methodical rigour and praxis orientation, and guided by an objectivistic ideal of science. However, the latter was also challenged by panelists who enthusiatically appraised reflexive research that acknowledged the role of emotions in knowledge production.

The IFPM3 case shows that conferences offer a unique space for observing academic valuation practice. Exploring how scholars enact values through conference discourse will not only help to better understand the specificities of particular research fields and their epistemic cultures. It can also more generally enhance the understanding of how social and epistemic levels in science intersect.

Keywords: conferences; valuation; pragmatism; linguistics; forest research; emotions 


\section{Introduction}

When COVID-19 hit the world in 2020, it disrupted personal and professional routines and practices in almost all areas of society. In academia, one of the most routinised activity brought to a halt was conferencing. Physical gatherings of hundreds of scholars from different countries and continents as common before became unimaginable events from one day to the other. In the beginning, the cancellation of conferences made headlines. On 02 March 2020, Nature found it newsworthy to report:

"Coronavirus fears cancel world's biggest physics meeting." (Castelvecchi 2020)

However, rather than pausing with conferences, scientists quickly started to shift meetings into virtual space, obviously considering them too important to do without them for a while. This is remarkable in that conferences, unlike other activities, often do not bring tangible results. However, scientists are aware conferencing is essential for academic work. And in fact, bibliometric studies indicate that conference attendance has an impact on scholarly careers: especially the participation in international events is related with increased publication activity and involvement in cross-country collaboration (Prpić 2002; Hesli and Lee 2011; Wang et al. 2017; Kwok et al. 2018).

The role of conferences in knowledge production also manifests in their frequent mentioning as decisive events for joint publication and research projects, sometimes even for the formation of new fields (Vessuri and Canino 2002; Williams and Moore 2019; Henderson 2020). Reflexive conference reports, as published also in Science as Culture, are seen as giving insights into the current state of disciplines and their development (Barns 1995; Winner 1998; Worthington 2007).

While conferences are thus often referred to, they rarely feature as main site or subject of science studies. This is surprising as scholars have repeatedly pointed out 
their significance and simultaneous neglect (Söderqvist and Silverstein 1994; Vessuri and Canino 2002; González-Santos and Dimond 2015; Hauss 2018; Trøst Hansen and Budtz Pedersen 2018). During the pandemic, conferences appeared more often as topics of articles reflecting on how to make them more sustainable and inclusive in future (Remmel 2021; Sarabipour et al. 2021). However, empirical studies providing more indepth, theoretically grounded accounts of scientific conferences as sites of scientific practice are still scarce (Gross and Fleming 2011; Henderson 2020).

One of these rare examples has been published in this journal: Using the International Conference on Auditory Display as empirical case, Supper (2015) has explored the practice of 'data karaoke', in which sonification researchers use their own voice to orchestrate soundfiles in a conference setting. She shows that this multisensory bodily practice fulfuls multiple functions in scholarly presentations; at the same time, it challenges the dominant epistemological discourse which frames different sensory modalities as competitors. While conceding the peculiarity of her case, Supper concludes that studying performances at conferences "helps us to understand not only the conference cultures, but also the ideals about scientific scholarship and academic authority held by scientific communities" (p. 453).

Building on Supper's argument, I seek to enhance this understanding with a study that examines conferences as spaces of valuation that are constitutive of epistemic cultures in research fields. Drawing on conference research and valuation studies, I present a pragmatist approach to grasp how scholars enact and negotiate values at conferences. This approach focuses on analysing statements of reasoning and justification; questions and remarks; and evaluative emotional utterances (which may but not necessarily need to be part of the first two). I illustrate how these different types of speech acts can be analysed as evaluative acts with data generated through observing 
participation in a virtual forest policy research conference, the $3^{\text {rd }}$ International Forest Policy Meeting held in March 2021. I argue that researching conferences as spaces of valuation has the potential to enrich science, valuation and conference studies alike: Shifting the spotlight on a site of scientific practice that has so far received little systematic attention by STS researchers and valuation scholars, it opens up a new scene for ethnographic and comparative inquiry. Setting the focus on valuation as a social process related to the epistemic, it also adds a new layer to conference research.

I conceive conferences as unique spaces to observe valuation in action. In contrast to interview situations and group discussions often employed by valuation researchers, conferences constitute a professional setting in which scholars perform values through talk and interaction. While Supper (2015) in her study highlights the role of the body and senses in academic conferences, my analytical focus is on speech. The core question I ask is: How are values enacted in conference discourse and how can that be grasped?

My paper is structured as follows. In the first section, I delineate the strands of scholarship this study builds on, namely conference research and pragmatist works in valuation studies. In the second section, I introduce forest policy research as field of investigation and describe my own involvement therein; further, I give details about how I conducted conference ethnography at an international forest policy research meeting, and sketch methodological premises guiding my analysis. In the third section, I present the pragmatic approach of researching conferences as spaces of valuation I developed through an iterative engagement with theoretical insights and empirical data. Finally, I elucidate how this approach may help to address broader questions in science and valuation studies, especially the linkage of valuation and inequalities that play out at conferences as sites of scientific practice. 


\section{Analytical Perspective: Conceptualising Conferences as Spaces of Valuation}

In this paper, I conceptualise conferences as spaces of academic valuation. Thereby, I build on conference and valuation studies - two STS-related research areas that share an interest in social aspects of science, yet to my knowledge have so far not entered into dialogue. Conference research highlights the significance of conferences as sites of scientific practice. Valuation studies substantiate the claim that scientific practice is permeated by evaluative acts, even though these often remain implicit. Studying valuation at conferences may offer an avenue to address open questions in both fields.

\section{The Significance of Meetings for Knowledge Production: Insights from Conference Research}

In an editorial of a special issue on conferences as gendered spaces of learning, knowledge production and community, Henderson and Burford (2020) object to the frequently made claim that conferences are still a neglected phenomenon in academic debates; however, they find that scholarship continues to be scattered and disconnected:

We can no longer lament that there is no attention paid to conferences, and neither can we complain that there is no research on conferences. Our respective forays into conferences research have revealed a substantial body of literature which focuses entirely or in part on the conferences phenomenon. The literature is dispersed across disciplines and is disparate in terms of method, orientation and approach (...). Furthermore literature on conferences often takes the form of reflective pieces (...) which do not carry the same weight as full-length articles, and much of the commentary on conferences is located in blog posts and grey literature. The same can be said of gender and feminist literature on conferences, which is similarly scattered and disconnected. (Henderson and Burford 2020, p. 2)

The dispersed nature of literature makes it difficult to provide a comprehensive overview of conference studies. Scholars making the effort to review and synthesize them have mostly done so with a focus on specific aspects, such as gender, inequality or 
the impacts of academic events (Trøst Hansen and Budtz Pedersen 2018; CoronaSobrino et al. 2020; Boncourt et al. 2021). Rather than providing a lengthy (and necessarily incomplete) literature survey, I focus on explicating core insights from existing scholarship that shape this study's analytical perspective on conferences.

First of all, conferences are sites of scientific practice which play a crucial role in the making and circulation of knowledge (González-Santos and Dimond 2015; Henderson 2020; Boncourt et al. 2021). They play this role by offering temporary spaces for direct encounters and exchanges between (aspiring) members of a research field who, if they are not direct colleagues or collaborators, communicate mainly through writing (if at all). Conferences allow for immediate interaction characterised by a particular intensity due to their distinct spatio-temporality (Pels 2003; González-Santos and Dimond 2015; Querfurt 2019). It is in these "thematically centred interaction systems" (Hitzler and Hornbostel 2014, p. 69; translated from German) where scholars experience an academic community in the literal sense, where they are introduced and socialised, where they get to know how to speak and what to ask - where they learn the tacit norms and hidden conventions of discourse in a specific community, and the interpretative repertoires to legitimate their claims (McKinlay and Potter 1987; Hitzler and Hornbostel 2014; Supper 2015). Facilitating face-to-face or virtual interaction of scientists, conferences thus provide for more than the exchange of information and ideas; they foster academic socialisation and identify-formation (Lomnitz 1983; Silverman 2002). They are sites where knowledge is performed and at the same time made in performances (Etzemüller 2019). The latter are not subsequent or secondary processes, but constitutive: Knowledge only becomes knowledge "when it appears as such through representation and staging, perception and mediality, interaction and authorisation among others, in the talk" (Peters 2011, p. 23; translated from German). 
Building on these works, I understand conferences as "constituting spaces of scientific fields" (Koch and Matviichuk 2021) in which social and epistemic dimensions of scientific practice converge. This convergence manifests in the fact that by presenting and discussing results and evidence, scholars negotiate what is worth knowing and which research is considered valuable.

\section{The Significance of Values in Academic Work: Insights from Valuation Studies}

How values are "produced, diffused, assessed, and institutionalized" (Lamont 2012, p. 202) in academic settings is a core theme of valuation studies. The latter have shown how evaluative decision-making takes place in peer review processes (Lamont 2009; Pontille and Torny 2015; Kaltenbrunner and de Rijcke 2019); on which grounds academics are assessed in appointment and recruitment procedures (Hamann 2019; Hammarfelt et al. 2020); and how quantitative metrics increasingly shape such evaluative processes, with which effects on research careers and knowledge practices (Fochler et al. 2016; de Rijcke et al. 2016; Felt 2017).

Such studies reveal some cross-cutting features of valuation in science but also show differences in valuation regimes: how worth is ascribed to research and what is recognised as valuable scholarship varies across disciplines and epistemic cultures (Hammarfelt 2017; Hessels et al. 2019). There have been repeated calls for more research on how value is constructed in different research communities, and what accounts for the observed variation (Angermuller 2017; Hamann et al. 2018).

Dussauge et al. (2015b) have proposed valuography as an empirically oriented research programme to study the making of values. In line with pragmatist scholarship in the tradition of Dewey, they propose to understand values as enacted rather than something fixed and stable. Such an understanding implies a shift from values to 
valuation as object of study (Dewey 1939; Brosch and Sander 2015; Heinich 2020). It also means that the "primary focus is not so much on how values might guide the scientific gaze, but instead on how values are formed and articulated in, for instance, processes of valuation in relation to the epistemic" (Dussauge et al. 2015a, pp. 13-14).

I consider conferences to be unique sites for exploring such processes because they allow for an observation of valuation in action. At scientific meetings, it comes to the fore what matters for scholars in a given field, which aspects and kinds of research they consider worthy of being addressed and discussed with peers. Conferences are spaces where the making of values happens in the discoursive interaction of participants. In this study, I seek to explore how values are enacted and articulated in research discussions at scientific conferences. Thereby, I develop a pragmatic approach to analyse conference talk observed at a forest policy research meeting.

\section{Case Study Background and Methodology}

In contrast to many life sciences, forest policy research has so far hardly received attention by science scholars, except from those who are themselves part of it (yes, such do exist, but they are few). In the first part of this section, I elucidate what the field is concerned with and how I came to enter it. (Spoiler: Conference attendance played a significant role in that). I then describe how I conducted conference ethnography at the $3^{\text {rd }}$ International Forest Policy Meeting and which sort of data I generated. Lastly, I sketch methodological premises underlying my engagement with the empirical material.

\section{Forest Policy Research Conferences and My Own Involvement Therein}

Forest policy research is a scientific field of critical relevance. The knowledge it generates informs scientific forestry and policy-making in various sectors - from forest 
and land use governance to environment and climate politics - at international and national levels. Contrary to what the name implies, it is concerned with much more than forest policy in the literal sense. Broadly speaking, it examines all aspects of how forests are governed, managed and used by societies across the globe, and the socioecological effects this has. As an emerging field related to but also distinctive of other more natural science based forest research areas, it covers a wide range of topics addressed by scholars with various disciplinary backgrounds. Members of the field use a multitude of social science methods and work across a range of institutions not all of which have 'forest' in their title. What unites this diverse community of scholars is their common interest in forest-related issues.

I encountered this community first in 2016 when I got a post-doc position at the Chair of Forest and Environmental Policy of the Technical University of Munich, which is a well reputed institution in the field. ${ }^{1}$ One of the first things the head of my department suggested when I started was to call the organiser of an upcoming conference - the first International Forest Policy Meeting - and ask if I could still register although the deadline had already passed. I followed his advice, and shortly after found myself in an old castle in Northern Germany, quite nervously introducing myself to a hall full of scholars in a so-called 'speed introduction round' where every conference participant was asked to stand and speak up for a minute. I remember refering to my colleague sitting next to me to legitimate my presence ('I am a colleague

\footnotetext{
${ }^{1}$ In my $\mathrm{PhD}$, I had investigated expert advisory processes in developing democracies, whereby
} one focus was on forest and environmental policy-making in South Africa and Tanzania. However, I had done so from a sociology of science perspective and presented results initially at African and development studies conferences, so didn't have a link to the forest research community before starting as post-doc at the TUM Chair. 
of $\mathrm{X}$ at TUM...I am a newcomer to this community and excited to join this event...'). The event turned out to be exciting for me indeed: Not only was I presented with topics I had never heard of before, but also with a sense of community and collectivity I had never sensed before, which I noticed during conference sessions but also joint meals and the excursion into a primeval forest nearby.

I describe this personal experience in such detail to explain my interest in understanding what happens at scientific conferences, and to disclose my involvement in the empirical field of this study. Over the past years, I have participated in at least six forest policy research conferences as presenter or session chair, and attended additional ones without an active role. I have published in one of the community's core journals which I was asked to join as editorial advisory board member, and I have established personal relations with a range of colleagues.

My own position and experiences in the field certainly disqualify me for acting as a neutral observer. While some may see this as a weakness, I experienced my involvement as a resource: It not only helped me to establish a rapport that helped to conduct conference ethnography but also to gain a deeper understanding of the relevance and reference frames structuring the field.

\section{Conducting Conference Ethnography at the $3^{\text {rd }}$ International Forest Policy}

\section{Meeting}

I generated the empirical data for this study as an observing participant of the $3^{\text {rd }}$ International Forest Policy Meeting (IFPM3) which took place from 17.-18. March 2021. Due to the pandemic situation, it was a fully virtual conference for the first time, which of course affected how it could be ethnographically researched. Obviously, many crucial aspects of conferences, such as the sensory and bodily experiences described by Supper (2015) and the social encounters happening in coffee breaks, at dinners or joint 
excursions - at forest policy research conferences usually a fixed item on the programme - either do not take place or disappear from sight.

However, while some forms of interaction are missing or elude observation in the digital space, I found that new stages of communication open up, such as the chat which sometimes became a sort of discursive side-stage of discussions and developed an own dynamic while the communication on the 'main stage' (i.e., the moderated conversation between speakers and audience mediated by video and audio) continued. Moreover, the fact that I could access recordings of presentations and, given consent of participants, include them into the analysis significantly enlarged the scope of my material. ${ }^{2}$ The latter finally comprised different types of text: the book of abstracts, chat comments and field notes complemented with partial transcripts from recordings. As these only captured the talks and not the Q\&A parts of sessions, I reconstructed audience reactions in the panels on the basis of extensive jottings noted down while listening to the discussion that emerged after presentations. I draw on these data to illustrate how values are enacted in a conference setting, and how they can be reconstructed from the text materials.

\section{Methodological Premises}

My engagement with the conference materials compiled is inspired by pragmatic approaches that focus on language and interaction as instances of meaning-making. ${ }^{3}$ In

\footnotetext{
${ }^{2}$ Upon request of the conference organisers, I not only informed all participants about my study via email, but I also asked them for their explicit consent to make observations during their panels and to use recordings if they had agreed to such.

${ }^{3}$ For an overview of the several pragmatist traditions in philosophy and social sciences and their different foci and assumptions, see Bowen et al. (2020, pp. 2-3)
} 
the tradition of American Pragmatism, I take it that "[what] people say and how they say it documents a social action performed with regard to their counterparts' assumed perceptions and reactions" (Bethmann et al. 2018, p. 97). This premise requires a methodology that pays attention to the speaker's and the addressee's verbal and nonverbal contributions as well as the situation in which these are made.

As suggested by Heinich (2020), I focus on the close observation of the operations by which actors actually manifest the value they assign to things; this focus on acts involves a focus on speech acts as studied by pragmatic linguistics (Searle 1980; Capone 2013). I particularly borrow from linguistic works that specify how valuation happens in conversation and argumentation, and how emotions play a role therein (Fiehler 1993; Hartung 2000; Fiehler 2002; Mackenzie and Alba-Juez 2019). Equipped with insights from these works, I set off to grasp how scholars enact values in conference discourse.

\section{Empirical Analysis: Evaluative Acts in Conference Talk and Text}

As stated previously, I follow Dussauge et al. (2015a) in their pragmatic perspective on values as "something grappled with, articulated, and made in concrete practices" (p. 1). The core question of my study has thus been how values are articulated and made in the context of conferences as spaces of scientific practice and 'live' knowledge production. Analysing materials from IFPM3, I identified three different types of evaluative acts in conference text and talk, namely: statements of reasoning and justification; questions and remarks; and evaluative emotional utterances (which may be but do not need to be part of the first two). In the following, I will explain how valuation takes place therein, illustrated with examples from the conference under study. 


\section{Statements of Reasoning and Justification}

While scientists rarely explicate values guiding their research (because this is not common or because they do not reflect upon these themselves), they usually provide reasons for the studies conducted. Statements of reasoning and justification are part of the communicative standard repertoire of researchers. Across all disciplines, they need to demonstrate the relevance of their research to different audiences, including funders, the public or their peers. The way how this is done, and which value propositions are enacted in the construction of relevance, has been shown to be highly context- and fielddependent (Hessels and van Lente 2011; Long and Foster 2013; Huber 2020).

Conferences are particularly useful for grasping field-specific patterns in this regard precisely because of the specific setting and the conditions of discourse happening therein. Given the standard timeslot of about fifteen to twenty minutes per presentation, scientists have to make choices about which story to tell, what to highlight and what to leave out, and their choices are shaped by the expected audience. At academic conferences, this audience may comprise different types of professionals, ranging from scholars to practitioners and policy-makers, but for the most part usually consists of academics; unless events are explicitly addressing 'external' stakeholders, scientists primarily communicate to (potential) members of a scientific field, and their talk is designed to be heard by peers (McKinlay and Potter 1987). ${ }^{4}$

In giving their talks, they provide rationales highlighting the relevance of their research. These rationales entail value performances: they reflect what scientists

\footnotetext{
${ }^{4}$ Audiences at academic conferences certainly vary and may comprise practitioners, policymakers, patients and other 'non-scientific' groups; for analysing conferences, it is important to take into account what kind of event serves as site of investigation.
} 
consider legitimate justifications for doing research. These research justifications may not be congruent with individual motivations - they are performed for 'the field', and thus reflect value propositions scholars assume to be valid and important therein.

Statements of reasoning and justification are given especially at the beginning of talks and written abstracts where researchers outlined what made them to pursue their study, as the following examples illustrate:

Good morning from my side. I would like to talk about mountain forest policies. So we go to the Alpine region, so that's, we have here a new strategy of the EU, the [name of the strategy]. And this new institution has to search a little bit more for what they are doing. Because we have the Alpine convention where all the actors already work together, and here we have a relatively practical project which tries to get in contact with the, the regional actors, and also want to compare the policies between the Alpine countries. We used a relatively practical approach and we tried to define different policy issues and want to learn how the actors perceive policy change, perceive, use steering tools and perceive which actors are involved in policy fields. So the background is we would like to identify what could be the role of the new strategy... (Introduction Presentation A)

And now a few words about our research, ah, research project and our case study research. It's also important for you to know that this was actually this was already the THIRD step in our project, the third research step, and in this research or within this research, we built on previous steps where we conduct the workshop with the project stakeholders and we conduct a literature review on the drivers for integrated forest management. And these previous steps allowed us to formulate our research questions here. We wanted to understand how do forest managers and experts understand and practice the integration of nature conservation into forest management in different contexts in Europe? And then we want to take a look, we want to understand what is facilitating and what is impeding the integration of nature conservation measures into forest management in different European contexts. (Extract Presentation B)

Over the past years, foresters working for the public forest administration in [X] increasingly find themselves under pressure to preserve their traditional epistemic 
authority over forestry issues, being confronted with ecological challenges related to climate change and the loss of biodiversity. Dropped wood prices endanger the classical and well-oiled cooperation with the timber industry, which in the past generated relatively stable public revenues. These developments frame a rapid devaluation of scientific forestry's traditional knowledge, and its application, in public forest management. The public forest administration is often criticized for being backward-oriented and not adapting rapidly enough, despite efforts to implement and update its multi-purpose management framework. Under these circumstances, this study zooms in on particular knowledge practices in public forest management in southwest [X]. It asks what foresters on different administrative levels actually do to 'create' the forest and its multiple purposes as known by the forest administration. (Abstract C)

The identification of values enacted in such statements of reasoning and justification requires an analytical step of abstraction that looks into causes given for conducting a study and how these are being presented. In the first example provided above, the presenter starts by relating the research subject to a new EU strategy put in place which 'has to search a little bit more for what they are doing'; his project intends to support this search by grasping perceptions of actors affected and involved. ${ }^{5}$ A similar justification for research is given in presentation B. Again, the reference is made to forest actors faced with a particular task - here, the integration of nature conservation into forest management - and research is carried out to understand their understanding of it, as well as to identify 'what is faciliating and what is impeding' this task in their respective country contexts.

The third text is a written abstract of an oral presentation in full length. The point of departure are the foresters who find themselves under pressure to maintain

\footnotetext{
${ }^{5}$ In making this case, it is noticeable how the speaker for one employs the collectivising 'we' throughout his introduction, whereby he doesn't clarify specifically who is is included therein; however, this 'we' is facing a new institution in need of support in finding its role.
} 
epistemic authority while being confronted with multiple challenges. Their severe situation - they are doing their best yet are constantly being criticised and devalued (although it is not specified by whom) - is used as a justification for an exploration of knowledge practices in public forest management which asks what they 'actually do'. In all three cases, the social world of forest actors serves as starting point of research. The specific projects are justified with challenges and new developments faced by actors in the forest sector (like being confronted with a new EU policy or public criticism); this reference suffices to legitimate studies, whereby scholars emphasise how these will help to deal with the situations.

This sort of justification was a recurring pattern in my material. I read it as a valuation of research that is being oriented and supportive of practice. Scholars make a stance for their research and construct its relevance by referring to current developments that challenge forest actors and by outlining how their studies may help these in coping with these. Through their legitimations, they ascribe worth to a certain type of scholarship that is responsive to the needs of forest actors and solution-oriented.

Now one could fairly say, well, this is neither too surprising nor spectacular in a field with an applied orientation, and I would agree. But that's not the point. What I wanted to illustrate is that statements of reasoning and justification made in conference talk and text enact certain values that have a bearing on the epistemic. In the case of forest policy research, the valuation performed at conferences renders scholarship as valuable that can provide concrete recommendations for how to tackle sectoral problems. This property of research has repeatedly been emphasised in conference discourse, especially also the interaction following talks. 


\section{Questions and Remarks}

The time for questions and remarks following talks is usually quite limited, at least in the formal part of conferences which often have a tight programme and schedule. However, again the point can be made that it is precisely this setting which makes them fruitful for an analysis of valuation: While certain communicative scripts apply (like starting an interrogative comment by saying 'thanks for the interesting presentation' in English-speaking events, which might be more an indication of knowing the culturallinguistic habitus than an expression of appreciation), scholars that have been listening can in principle ask or comment on any aspect of the presentation they consider worth discussing. They may challenge the theoretical perspective adopted, ask for more details on the methodology, praise the innovativeness of the approach, express sceptisicm about the conclusions drawn, or confront the speaker with their own works on the topic (which happens not too rarely). By making remarks, scholars stage and position themselves (Hitzler and Hornbostel 2014; Querfurt 2019). At the same time, they signal and negotiate what counts as good research and which aspects of it are considered crucial for qualification as such.

At the IFPM3, two recurring themes of questions and remarks were the implementation of methods and practical implications of results. The following examples give an idea of how these were addressed, and how I captured them in field notes (as discussions were not recorded):

After the last presentation, the session chair announces that the remaining time is open for questions and comments. [X], who is a well-known scholar, raises her hand and is encouraged to speak by the moderator. She first directs a question at the second speaker, asking her to elucidate why she has chosen to use [Y] as a theoretical concept which she finds quite unusual and not necessarily applicable to the study context presented. Secondly, she turns to the last speaker, stating that colleagues and herself have recently analysed a couple of policy documents 
including the strategy the speaker focused on. She says she is 'quite surprised' that the speaker found actor positions in policy strategies as these normally are negotiated texts, not always, but mostly made by governments; for the strategy under study, she would 'know' that it had been a result of a participatory process, but she assumes 'you have analysed much more documents'. The tone of her voice is friendly but doesn't hide her scepticism and criticism of the approach employed. (Field note A: start of panel discussion)

The panel is about to close as the time is almost up, but the moderator allows for a last question. She invites a person to speak who has already posted her question in the chat, namely "what are the practical impacts of of decolonization/degrowth concepts?' The interrogator is a younger $\mathrm{PhD}$ candidate. She elaborates that she really 'likes the idea about degrowth' and thinks it is 'a radical movement'. However, as she perceived the presentation as 'very theoretical', she asks for the practical insights of degrowth. The moderator who is also the presenter addressed makes a deep sigh. (Field note B: last question in discussion)

Dear [first name of presenter], thanks a lot for great presentation, indeed. Very interesting data! I am curious to know whether you have identified what can be changed in the existing urban forest infrastructures you explore for getting green areas that are more effective in providing well-being and health positive effects. For example, you mentioned tranquillity: is there any options to make these places more quiet/less noisy? Thanks. (Chat comment C)

In the first example above, a scholar who is a well-known figure in the field, challenges the two speakers she addresses in her remarks - the first for the uptake of a rather 'unusual' theory, the latter for the methodology employed. As to the latter, she backs her critique with her own expertise and experience in that sort of analysis; while she conveys her criticism in a friendly tone, it becomes quite clear in her lengthy elaboration that she calls the validity of the approach presented into question.

This scene is exemplary in that method-related questions took up a lot of space in conference talk. Forest policy researchers extensively discussed how data were obtained, to what extent they were (or weren't) representative, what had been done to 
avoid bias, and in what ways they were generalizable. ${ }^{6}$ In contrast, theoretical implications were rarely addressed or challenged. Putting an emphasis on the practicalities of data collection and analysis in their discourse, forest policy researchers foregrounded methodical rigor as a central aspect of good scholarship. I am using the word methodical, and not methodological, by intention, as discussions centered mostly on how things were done, and less on the relation of methods and theory.

When theory was discussed, its potential for practice mattered, as in the situation captured by field note B where a PhD student asks for the practical insights the concept of degrowth may generate. This question was a pervasive one during the meeting. In chat comment 3 , the expection of concrete recommendations resulting from research (here: how to make urban forests less noisy and thus more effective in providing wellbeing) is made even more explicit. I posit that such patterns in terms of what scholars ask and comment upon at conferences are not random. Discursive contributions are shaped by expectations about what counts in a field. At the same time, questions and remarks enact value properties of good scholarship - such as praxis orientation and methodical rigour.

\section{Evaluative Emotional Utterances}

With evaluative emotional utterances, I refer to speech acts that articulate affects and explicit or implicit value ascriptions. As linguistic scholars have pointed out, emotional expressions inherently entail evaluating statements (Fussell 2002; Fiehler 2002; Alba-

\footnotetext{
${ }^{6}$ In many situations, these discussions had the character of collegial rather than critical exchanges. The tone of most discussions was not sharp or challenging, but curious and understanding. I consider the strong sense of community constructed at forest policy research meetings as remarkable and worthy of being examined further.
} 
Juez 2019). They express a speaker's stance towards a situation, a person, someone's actions, events and circumstances on the basis of her expectations, social norms and values which form her frame of reference (Fiehler 2002).

Scholars tend to avoid emotional judgements when communicating their research in the form of publications. Even in opinion or perspective articles, authors are careful to hold back their emotions and instead justify their positioning with rational arguments. While scientists usually refrain from articulating emotions in scholarly writing, they do explicate them in the social space of conferences by using literal and figurative expressions of appreciation, scepticism, rejection, and so on. My material offers plenty of examples ranging from statements made in presentations to comments posted in chats, which had a particularly enthusiastic tone:

You see South of the city that there is a beautiful forest called the [name of forest], and that's the one that I will focus on today. (Statement A, made by a presenter in the introduction of the talk)

Thank you, [first name of presenter], for your impressive presentation. I am really impressed by the scope of your research and the amount of data collected.

(Comment B made in reaction to presentation)

Thank you for giving me the floor and for the whole panel for brightening my day - I am speechless and would have plenty of questions but I reduce myself to one. (Comment $\mathrm{C}$ during discussion)

Blown away, literally, by the quality of these presentations!!! One of the best sessions I've ever been in. super presentations - cant agree more with X.

(Comments D, posted in the chat during the course of the panel)

As the examples illustrate, scientists made evaluative emotional utterances in various discursive moments - within and during talks as well as in response to these. Screening 
my material, I identified them by looking for evaluative and emotive descriptors, but I also relied on my field notes where I had marked nonverbal cues that caught my attention while listening and watching, such as facial expressions, a change in the tone of voice, etc. These on-site notes proved to be pivotal for making sense of the communication taking place, especially by indicating the atmosphere of discourse and its dynamics.

After identifying evaluative emotional utterances in my material, I tried to reconstruct what they were directed at. In statement A, this is quite straightforward: A speaker introduces his case study site by describing the forest as beautiful - an affective qualification of the forest which is seldom found in research articles, but repeatedly made at forest policy research conferences.

In comment $\mathrm{B}$, the speaker explicates twice how impressed he is by 'the scope of research and the amount of data collected'. He refers to a study which, according to the presenter, included 186 key informant interviews and content analysis of more than seventy documents. It is of various examples where scope was enacted as valuable research property (the more interviews the better/the more impressive) whereby interestingly, the appreciation of quantity even concerned studies of scholars presenting their works as qualitative social science research.

Comments $\mathrm{C}$ and $\mathrm{D}$ were all made in the same panel, the first as an oral remark and the others posted in the chat, which entailed even more enthusiastic notes, ranging from 'super inspiring' to 'really cool'. Of course, the comments as such do not disclose what caused this excitement, aside from the fact that they highlight the "quality of presentations' and the panel as such. Hence, a contextualisation is required.

The panel in which the comments were made focused on knowledge practices, a not so mainstream topic in forest policy research. It was set up by a group of scholars, 
including post-docs, $\mathrm{PhD}$ candidates and professors of younger age, who had jointly produced and contributed a special issue based on their works. The studies presented differed from what I consider dominant scholarship in the field in that they employed mostly qualitative (auto-) ethnographic methodologies. In the course of the panel, the focus more and more shifted to an engaged discussion on the role of emotions and affects for knowledge production, and the atmosphere of talk became noticably intense. The discourse culminated in a forest policy researcher giving a very personal insight into identity struggles he experienced during his professional training which he perceived as repressing all emotional-creative aspects of engaging with trees important to him.

What happened in this panel was a collective valuation of reflexive scholarship that departs from dominant forest policy research in that it emphasises the social in the epistemic, and challenges the objectivistic ideal of scientificity prevailing in the field. The emotional comments made in the panel were signifiers of this process. I take this as an example that illustrates two core points: first, that values are indeed not fixed, but made in interaction; and second, that conferences offer spaces of interaction in which scientists - in the above example, forest policy researchers representing a younger generation - redefine the properties attributed to valuable science.

\section{Conclusion}

Conferences are not only sites of knowledge exchange, but of scientific valuation practice: In discursive interaction, scholars (re-) negotiate what counts as good research, what kind of scholarship is considered valuable and which epistemic properties matter for their field. I make this argument building on conference research and valuation studies that highlight the significance of scientific meetings for knowledge production, 
and the significance of values in academic work. Moreover, I draw on conference ethnography conducted at the $3^{\text {rd }}$ International Forest Policy Meeting (IFPM3), an international forest policy conference which serves as empirical site of investigation.

The methodology I suggest for researching conferences as spaces of valuation borrows from pragmatic linguistics to identify evaluative acts in conference talk and text. Analysing field notes, transcripts from recordings, chat comments and abstracts of the $3^{\text {rd }}$ International Forest Policy Meeting (IFMP3), I identified three types of such evaluative acts: statements of reasoning and justification, questions and remarks, and evaluative emotional utterances. Focusing on such evaluative acts in my material, I illustrated how forest policy researchers ascribe worth to scholarship characterised by certain properties, such as praxis orientation and methodical rigour. Using the example of a panel on knowledge practices which challenged the prevailing ideal of objectivistic science, I also showed that conferences offer discursive moments in which scientists may renegotiate what they consider valuable properties of research.

My study shifts the spotlight on a site of scientific practice which is still niche subject of STS, despite its impact on individual and collective research trajectories. While practices like laboratory work, peer reviewing and publishing are extensively investigated, conferencing is rarely made the main subject of research. Science and valuation scholars seem to use conferences mostly as entries or side-stages of empirical investigation; observation of scientific meetings are often mentioned as one among other methods, but they - unfortunately - often disappear in results sections where evidence is substantiated with interview or focus group discussion quotes. Moreover, as noticed by González-Santos and Dimond (2015), there is little methodogical reflection and transparency on how conference data are used and analysed. The pragmatist 
approach I propose puts conferences center stage, and shows one way of analysing what happens at these important events.

Conferences offer a unique space for observing scientific practice and valuation in action. Exploring how scholars enact values through communicative interaction will not only help to better understand the specificities of particular research fields and their epistemic cultures (such as, in my empirical case, that of forest policy research). It can also help to enhance the understanding of broader issues, such as how social and epistemic levels in science intersect (Baur et al. 2016).

To give a concrete example: I have started this research bothered by the puzzle that despite all policies and measures in place to make conferences more inclusive, they continue to be sites where social and epistemic inequalities are reproduced (Blumen and Bar-Gal 2006; Derudder and Liu 2016; Ford et al. 2019; Sabharwal et al. 2020; Timperley et al. 2020; Boncourt et al. 2021; Koch and Matviichuk 2021). While certainly tangible factors like funding, the possibility to travel etc. are still a major cause of persisting imbalances, the insights I get from forest policy research indicate that prevailing valuation in the field, guided by internalised norms and ideals of scholarship, may contribute to maintaining them, with substantial effects on the knowledge produced and recognised.

Values enter into science in many ways. This is not problematic per se, but becomes an issue when the latter remain implicit and not reflected upon (Longino 2004; Machamer and Wolters 2004; Elliott 2017). The pragmatic approach presented in this paper offers a way to elucidate valuation in conferences which, whether face-to-face, online or in hybrid form, will continue to play a crucial role as sites of scientific practice. 


\section{References}

Alba-Juez, L. (2019) Emotion and appraisal processes in language. In: J.L. Mackenzie and L. Alba-Juez, eds. Emotion in Discourse (Amsterdam: John Benjamins Publishing Company), pp. 227-250.

Angermuller, J. (2017) Academic careers and the valuation of academics. A discursive perspective on status categories and academic salaries in France as compared to the U.S., Germany and Great Britain, Higher Education, 73 (6), pp. 963-980.

Barns, I. (1995) Manufacturing consensus? Reflections on the UK national consensus conference on plant biotechnology, Science as Culture, 5 (2), pp. 199-216.

Baur, N., et al. (2016) Wissenschaft als Mehrebenen-Phänomen. Der Makro-MesoMikro-Link in der Wissenschaft. In: N. Baur, et al., eds. Wissen - Organisation Forschungspraxis. Der Makro-Meso-Mikro-Link in der Wissenschaft (Weinheim, Basel: Beltz Juventa), pp. 13-45.

Bethmann, S., et al. (2018) Forestry in interaction. Shedding light on dynamics of public opinion with a praxeological methodology, Forest Policy and Economics, 96, pp. 93-101.

Blumen, O., and Bar-Gal, Y. (2006) The Academic Conference and the Status of Women. The Annual Meetings of the Israeli Geographical Society*, The Professional Geographer, 58 (3), pp. 341-355.

Boncourt, T., Koch, S., and Matviichuk, E. (2021) International scientific associations and conferences as agents in the unequal circulation of knowledge. Manuscript in peer review.

Bowen, J.R., et al. (2020) Introduction. In: J.R. Bowen, et al., eds. Pragmatic Inquiry (Abingdon, Oxon, New York|: Routledge), pp. 1-14. 
Brosch, T., and Sander, D. (2015) From values to valuation: an interdisciplinary approach to the study of value. In: T. Brosch and D. Sander, eds. Handbook of Value (Oxford University Press), pp. 397-404.

Capone, A., ed., 2013 Perspectives on linguistic pragmatics (Cham, Heidelberg: Springer).

Castelvecchi, D. (2020) Coronavirus fears cancel world's biggest physics meeting, Nature News March 02.

Corona-Sobrino, C., et al. (2020) Closing the gender gap at academic conferences: A tool for monitoring and assessing academic events, PloS one, 15 (12), pp. e0243549. de Rijcke, S., et al. (2016) Evaluation practices and effects of indicator use-a literature review, Research Evaluation, 25 (2), pp. 161-169.

Derudder, B., and Liu, X. (2016) How international is the Annual Meeting of the Association of American Geographers? A social network analysis perspective, Environment and Planning A: Economy and Space, 48 (2), pp. 309-329.

Dewey, J. (1939) Theory of valuation (Chicago: University of Chicago Press).

Dussauge, I., et al. (2015a) On the omnipresence, diversity, and elusiveness of values in the life sciences and medicine. In: I. Dussauge, C.-F. Helgesson, and F. Lee, eds. Value practices in the life sciences and medicine (Oxford: Oxford Univ. Press), pp. 1-28.

Dussauge, I., Helgesson, C.-F., and Lee, F., eds., 2015b Value practices in the life sciences and medicine Oxford: Oxford Univ. Press.

Elliott, K.C. (2017) A tapestry of values. An introduction to values in science (New York, NY: Oxford University Press). 
Etzemüller, T. (2019) »It’s the performance, stupid «Performanz $\rightarrow$ Evidenz: Der Auftritt in der Wissenschaft. In: T. Etzemüller, ed. Der Auftritt. Performanz in der Wissenschaft (Bielefeld: transcript; transcript Verlag), pp. 9-43.

Felt, U. (2017) Under the Shadow of Time: Where Indicators and Academic Values Meet, Engaging Science, Technology, and Society, 3, pp. 53-63.

Fiehler, R. (1993) Grenzgänge des Argumentierens - 'Emotionalität statt Argumentation' oder 'emotionales Argumentieren'? In: B. Sandig and U. Püschel, eds. Germanistische Linguistik /Stilistik: Band III: Argumentationsstile (Hildesheim: Olms), pp. 149-174.

Fiehler, R. (2002) How to do emotions with words: emotionality in conversations. In: S.R. Fussell, ed. The verbal communication of emotions. Interdisciplinary perspectives (Mahwah, NJ: Erlbaum), pp. 79-106.

Fochler, M., Felt, U., and Müller, R. (2016) Unsustainable Growth, Hyper-Competition, and Worth in Life Science Research. Narrowing Evaluative Repertoires in Doctoral and Postdoctoral Scientists' Work and Lives, Minerva, 54, pp. 175-200.

Ford, H.L., et al. (2019) Women from some under-represented minorities are given too few talks at world's largest Earth-science conference, Nature, 576 (7785), pp. 32-35.

Fussell, S.R. (2002) The Verbal Communication of Emotion: Introduction and Overview. In: S.R. Fussell, ed. The verbal communication of emotions. Interdisciplinary perspectives (Mahwah, NJ: Erlbaum), pp. 1-16.

González-Santos, S., and Dimond, R. (2015) Medical and Scientific Conferences as Sites of Sociological Interest: A Review of the Field, Sociology Compass, 9 (3), pp. $235-245$. 
Gross, N., and Fleming, C. (2011) Academic Conferences and the Making of

Philosophical Knowledge. In: C. Camic, ed. Social knowledge in the making (Chicago: Univ. of Chicago Press), pp. 151-179.

Hamann, J., et al. (2018) Aktuelle Herausforderungen der Wissenschafts- und Hochschulforschung. Eine kollektive Standortbestimmung, Soziologie, 47 (2), pp. 187203.

Hamann, J. (2019) The making of professors. Assessment and recognition in academic recruitment, Social Studies of Science, pp. 1-23.

Hammarfelt, B. (2017) Recognition and reward in the academy, Aslib Journal of Information Management, 69 (5), pp. 607-623.

Hammarfelt, B., Rushforth, A.D., and de Rijcke, S. (2020) Temporality in Academic Evaluation, Valuation Studies, 7 (1), pp. 33-63.

Hartung, M. (2000) Überlegungen zur Untersuchung von Bewertungsprozessen in Gesprächen. In: I.H. Warnke, ed. Schnittstelle Text: Diskurs. Enthält die textlinguistischen Beiträge zum 32. Linguistischen Kolloquium, das vom 16. bis 18. September 1997 an der Universität Kassel im Fachbereich Germanistik stattfand (Frankfurt am Main: Lang), pp. 119-131.

Hauss, K. (2018) Der Nutzen wissenschaftlicher Konferenzen in der Nachwuchsausbildung (Wiesbaden: Springer Fachmedien Wiesbaden).

Heinich, N. (2020) A Pragmatic Redefinition of Value(s): Toward a General Model of Valuation, Theory, Culture \& Society, 37 (5), pp. 75-94. 
Henderson, E.F. (2020) Gender, definitional politics and 'live' knowledge production.

Contesting concepts at conferences (New York, London: Routledge, Taylor et Francis Group).

Henderson, E.F., and Burford, J. (2020) Thoughtful gatherings. Gendering conferences as spaces of learning, knowledge production and community, Gender and Education, 32 (1), pp. 1-10.

Hesli, V.L., and Lee, J.M. (2011) Faculty Research Productivity. Why Do Some of Our Colleagues Publish More than Others? PS: Political Science \& Politics, 44 (02), pp. $393-408$.

Hessels, L.K., et al. (2019) Variation in Valuation: How Research Groups Accumulate Credibility in Four Epistemic Cultures, Minerva, 57 (2), pp. 127-149.

Hessels, L.K., and van Lente, H. (2011) Practical Applications as a Source of Credibility: A Comparison of Three Fields of Dutch Academic Chemistry, Minerva, 49 (2), pp. 215-240.

Hitzler, R., and Hornbostel, S. (2014) Wissenschaftliche Tagungen - zwischen Disput und Event. In: C. Behnke, D. Lengersdorf, and S. Scholz, eds. Wissen - MethodeGeschlecht. Erfassen des fraglos Gegebenen (Wiesbaden: Springer Fachmedien Wiesbaden), pp. 67-78.

Huber, L. (2020) Relevanz. Über den Erkenntniswert wissenschaftlicher Forschung (Hamburg: Meiner).

Kaltenbrunner, W., and de Rijcke, S. (2019) Filling in the gaps: The interpretation of curricula vitae in peer review, Social Studies of Science, 49 (6), pp. 863-883. 
Koch, S., and Matviichuk, E. (2021) Patterns of inequality in global forest science conferences: An analysis of actors involved in IUFRO World Congresses with a focus on gender and geography, Forest Policy and Economics, 129, pp. 102510.

Kwok, E., et al. (2018) The collaborative effect of scientific meetings. A study of the International Milk Genomics Consortium, PloS one, 13 (8), pp. e0201637.

Lamont, M. (2009) How professors think. Inside the curious world of academic judgment. 1st ed. (Cambridge, Mass., London: Harvard University Press).

Lamont, M. (2012) Toward a Comparative Sociology of Valuation and Evaluation, Annual Review of Sociology, 38 (1), pp. 201-221.

Lomnitz, L. (1983) The Scientific Meeting: An Anthropologist's Point of View, $4 S$ Review, 1 (2), pp. 2-7.

Long, W., and Foster, D. (2013) The changing face of "relevance" in South African psychology, Psychology in Society (45), pp. 3-16.

Longino, H.E. (2004) How Values Can Be Good for Science. In: P. Machamer and G. Wolters, eds. Science Values and Objectivity (University of Pittsburgh Press), pp. 127142.

Machamer, P., and Wolters, G. (2004) Introduction. In: P. Machamer and G. Wolters, eds. Science Values and Objectivity (University of Pittsburgh Press), pp. 1-13.

Mackenzie, J.L., and Alba-Juez, L., eds., 2019 Emotion in Discourse (Amsterdam: John Benjamins Publishing Company).

McKinlay, A., and Potter, J. (1987) Model Discourse: Interpretative Repertoires in Scientists' Conference Talk, Social Studies of Science, 17 (3), pp. 443-463. 
Pels, D. (2003) Unhastening Science, European Journal of Social Theory, 6 (2), pp. 209-231.

Peters, S. (2011) Der Vortrag als Performance (Bielefeld: transcript).

Pontille, D., and Torny, D. (2015) From Manuscript Evaluation to Article Valuation:

The Changing Technologies of Journal Peer Review, Human Studies, 38 (1), pp. 57-79.

Prpić, K. (2002) Gender and productivity differentials in science, Scientometrics, 55 (1), pp. 27-58.

Querfurt, A. (2019) Wissenschaft auf der Bühne. Eine ethnographische Beobachtung von der Grenze aus. In: T. Etzemüller, ed. Der Auftritt. Performanz in der Wissenschaft (Bielefeld: transcript; transcript Verlag), pp. 177-202.

Remmel, A. (2021) Scientists want virtual meetings to stay after the COVID pandemic, Nature, 591 (7849), pp. 185-186.

Sabharwal, N.S., Henderson, E.F., and Joseph, R.S. (2020) Hidden social exclusion in Indian academia: gender, caste and conference participation, Gender and Education, 32 (1), pp. 27-42.

Sarabipour, S., et al. (2021) Changing scientific meetings for the better, Nature Human Behaviour, 5 (3), pp. 296-300.

Searle, J.R., ed., 1980 Speech act theory and pragmatics (Dordrecht: Reidel).

Silverman, S. (2002) The beast on the table. Conferencing with anthropologists (Walnut Creek, Calif.: AltaMira Press).

Söderqvist, T., and Silverstein, A.M. (1994) Participation in Scientific Meetings. A New Prosopographical Approach to the Disciplinary History of Science - The Case of Immunology, 1951-72, Social Studies of Science, 24 (3), pp. 513-548. 
Supper, A. (2015) Data Karaoke: Sensory and Bodily Skills in Conference Presentations, Science as Culture, 24 (4), pp. 436-457.

Timperley, C., et al. (2020) He moana pukepuke: navigating gender and ethnic inequality in early career academics' conference attendance, Gender and Education, 32 (1), pp. 11-26.

Trøst Hansen, T., and Budtz Pedersen, D. (2018) The impact of academic events - A literature review, Research Evaluation, 27 (4), pp. 358-366.

Vessuri, H., and Canino, M.V. (2002) Latin American Catalysis: As Seen through the Ibero-American Catalysis Symposia, Science, Technology and Society, 7 (2), pp. 339363.

Wang, W., et al. (2017) From triadic closure to conference closure: the role of academic conferences in promoting scientific collaborations, Scientometrics, 113 (1), pp. 177193.

Williams, L.D.A., and Moore, S. (2019) Guest Editorial: Conceptualizing Justice and Counter-Expertise, Science as Culture, 28 (3), pp. 251-276.

Winner, L. (1998) Report from the digital diploma mills conference, Science as Culture, 7 (3), pp. 369-377.

Worthington, R. (2007) Community-based Research and Technoscience Activism: A Report on the Living Knowledge 3 Conference, Science as Culture, 16 (4), pp. 475480. 